\title{
Absorptive Capacity And MNC Knowledge Transfer: The Organizational Behavior Perspective
}

Wei-Li Wu, Chien Hsin University of Science and Technology, Taiwan Yi-Chih Lee, Chien Hsin University of Science and Technology, Taiwan

\begin{abstract}
Many previous studies on internal knowledge transfer in multinational corporations (MNCs) have indicated that organizational absorptive capacity (AC) has a significant effect on knowledge transfer, but few scholars have dwelt on employee absorptive capacity. Employee $A C$ is fundamental to organizational AC. Therefore, employee AC is an important management issue. From an organizational behavior perspective, this study attempted to explore whether employees' personality traits, job characteristics and organizational environment had an impact on their absorptive capacity, hoping to develop a new research direction for the AC research realm.
\end{abstract}

Keywords: Absorptive Capacity; Organizational Behavior Perspective; Knowledge Transfer

\section{INTRODUCTION}

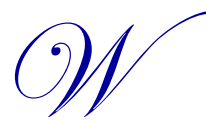

ith the advent of globalization, the economic activities of MNCs in the international market are becoming more and more active, including the search for low-priced raw materials and market development, as well as the extensive use of core competencies (Dunning, 1988). The internal network of MNCs is like a huge knowledge base through which overseas subsidiaries can exchange information with and learn from each other. In addition, scholars have even observed recently that subsidiaries have developed their own knowledge system based on their special network location, gradually repaying their home countries and, consequently, increasing the parent company's competitiveness (Björkman, Barner-Rasmussen and Li, 2004).

However, owing to the innate migration barriers of knowledge (Szulanski, 1996; Simonin, 1999), knowledge transfer is difficult. Prior studies have indicated that, for the knowledge absorbed to be effectively utilized, it depends on the absorber's absorptive capacity (AC) (Cohen and Levinthal, 1990; Minbaeva, 2005; Todorova and Durisin, 2007). Scholars' explorations of AC seemed to concentrate at firm level only. However, organizational members also play an important role of the executing agency in the process of knowledge transfer. Volberda, Foss and Lyles (2010) reviewed related literature on AC and pointed out that it is insufficient to research $\mathrm{AC}$ at the firm level only and that exploration of $\mathrm{AC}$ at the individual level is conducive to further understanding the concept of AC. As a matter of fact, individual level AC serves as the basis of firm level AC, so only with an indepth understanding of how to enhance individual levels of AC will it be possible to enhance firm levels of AC. Moreover, prior studies exploring how to enhance AC and knowledge transfer mostly focused on determining the antecedents of the inter-organizational level, such as the similarity and mutual trust between organizations (Lane and Lubatkin, 1998; Lane, Salk and Lyles, 2001). However, many intra-organizational levels of antecedents may significantly influence AC, such as its incentive mechanisms and communication systems (Volberda et al., 2010), yet we still lack research concerning intra-organizational antecedents. Therefore, looking into the intraorganizational antecedents that have an impact on AC is also a significant research issue. In this study, since individual level and organizational mechanisms are the focus of the research on $\mathrm{AC}$, the organizational behavior perspective was adopted for the subsequent theoretical analysis and development of propositions. Overall, this study attempted to focus on the absorptive capacity of employees in the process of knowledge transfer and, from the organizational behavior perspective, inferred the antecedents of employee AC. The goal is to propose a new research 
direction for the relationship between MNC internal knowledge transfer and AC. In short, the purposes of this study are as follows:

- $\quad$ To explore the relationship between employee AC and knowledge transfer

- To probe the antecedents of employee AC from an organizational behavior perspective

\section{LITERATURE REVIEW}

\section{Knowledge Transfer}

Stewart (1997) and Edvinsson et al. (1997) separated knowledge into human knowledge, structure knowledge, and customer knowledge, and classified these three categories of knowledge assets as the organization's intellectual capital; the higher the intellectual capital, the easier it is for a firm to succeed in a competitive environment. In other words, knowledge can constantly create advantages for the organization (Nonaka and Takeuchi, 1995; Davenport and Prusak, 1998). The proper utilization of organizational knowledge can bring sustainable competitiveness into the organization. Through internal networks, MNCs can conduct the best practice of knowledge transfer so as to increase the knowledge content of the whole organization and extend the use of core competency, thereby maintaining sustainable competitiveness in the global market (Björkman et al., 2004).

Badaracco (1991) assumed that a firm can join a social network where knowledge can be absorbed, created, stored, transferred, traded, and even swapped. According to Björkman et al. (2004), with complex and different networks linking together, MNCs thus have an internal network that acts as a cross-nation social network which enables the full transfer and exchange of different knowledge. In addition, during the process of knowledge transfer, the absorber is required to be able to develop, understand and absorb knowledge, as well as have the motivation to learn (Minbaeva, 2005). Therefore, this study focused on the relation between AC and knowledge transfer.

\section{Absorptive Capacity (AC)}

Cohen and Levinthal (1990) were the first to propose that the concept of AC included the ability for organizational identification, for absorbing external information of value, and the capacity for information application and commercialization. Cohen and Levinthal (1990) also pointed out that AC can be divided into individual and organizational levels. Individual level AC and organizational level AC are different, the former being the foundation of the latter. In addition, this study also proposed that $\mathrm{AC}$ is characterized by cumulative learning and can be described as a function of a firm's previous related knowledge.

In the past, scholars rarely explored $\mathrm{AC}$ at the employee level. However, the study by Minbaeva et al. (2003) on MNCs knowledge transfer concerning employee AC has indicated that employee AC does have a significant impact on knowledge transfer. Cohen and Levinthal (1990) also stated that organizational AC is based on individual AC; that is, individual AC is truly an important management issue. Therefore, the analysis in this study was focused on employee AC. In accordance with the argument of Minbaeva et al. (2003), AC was classified in two dimensions - employee ability and learning motivation. Hence, this study proposed that a high level of employee AC has a positive effect on knowledge transfer.

\section{Proposition 1: Employee absorptive capacity (ability/learning motivation) will increase the level of MNC knowledge transfer.}

Minbaeva et al. (2003) explored the effect of human resource practices on employee capacity and motivation from the human resource management (HRM) perspective. However, the mere adoption of the HRM perspective might result in an ignorance of the importance of employee personality traits and organizational design. From an organizational behavior perspective, this study attempted to include employee personality traits, job characteristics and organizational interaction mechanisms as the variables of employee $\mathrm{AC}$, hoping for a better understanding of employee AC and with the intention of opening a new research direction for the AC study realm. 


\section{Organizational Behavior Perspective}

Based on the organizational behavior perspective, this study intended to analyze the topics from three different dimensions - individual employee's personality traits, job characteristics and organizational environment and attempted to infer the effect of the three dimensions of employee AC.

\section{The Effect Of Personality Traits On Employee AC}

Each individual has his own different personality. When confronted with the same situation, individuals may have different modes of interpretation and action. Allport (1961) proposed that personality determines an individual's unique thoughts and behavior. Therefore, personality is an individual character and is unique. In addition to an individual's unique characteristics, personality is also reflected in all features and behavior patterns of an individual when they are adapting to their external environment.

In recent years, it has been fully confirmed that different personality traits will influence organizational members' performance in an organization. Additionally, the personality traits that influence organizational members have been identified as the Big-Five model, including dimensions of agreeableness, neuroticism, openness to experiences, conscientiousness, and extraversion (Robbins and Judge, 2011). Since the Big-Five model has completely covered personality traits, this study adopted the Big-Five personality traits that may impact on employee AC. Through a literature review of the Big-Five personality traits, it has been found that neuroticism, openness to experiences and conscientiousness may have distinctive effects on employee AC and are hereby described as follows:

\section{Openness To Experience}

Employees with a characteristic of high openness to experience are creative, fond of thinking, and have innovative ideas (Barrick and Mount, 1991; Costa and McCrae, 1992; Hsu, Wu and Yeh, 2011). They are not confined to tradition but often welcome freshness and novelty. Also, employees with a high level of openness to experience are fond of thinking and often have access to new knowledge, so it was inferred that they can easily enhance their own ability. In addition, owing to their spirit of innovation and curiosity, when faced with external knowledge, instead of showing hostility, they are likely to produce a high level of learning intention. Therefore, this study proposed that people with a higher level of openness to experiences, based on their own competency in many aspects, and their sense of curiosity for new knowledge, will show a higher level of AC.

\section{Proposition 2: Openness to experiences is positively correlated with employee AC.}

\section{$\underline{\text { Conscientiousness }}$}

People with a higher level of conscientiousness are generally highly responsible and achievement-oriented (Barrick and Mount, 1991; Costa and McCrae, 1992; Hsu, Wu and Yeh, 2011). Highly conscientious individuals tend to be stricter with themselves and thus work harder, striving for excellence; that is, highly conscientious individuals will keep on promoting their own ability in order to achieve a higher level of performance. In addition, motivated by the concept of achievement, people with a higher level of conscientiousness will have higher learning motivation for fulfilling their internal achievement-oriented needs. Hence, this study proposed that people with a higher level of conscientiousness, based on their individual principals and strong attempts at achievement, will show higher AC.

\section{Proposition 3: Conscientiousness is positively correlated with employee AC.}

\section{Neuroticism}

Highly neurotic people tend to be emotionally tense and anxious and frequently present negative and uneasy feelings (Barrick and Mount, 1991; Costa and McCrae, 1992; Hsu, Wu and Yeh, 2011); it is then inferred that their abilities in developing capacity is relatively low. On the other hand, neurotic people's inclination toward negative 
emotions may generate their distrust and hostile feelings while faced with external knowledge. Therefore, this study proposed that people with a higher level of neuroticism, owing to their relatively lower abilities in capacity building and tendency to distrust external knowledge, will produce lower AC.

\section{Proposition 4: Neuroticism is negatively correlated with employee AC.}

\section{The Effect Of Job Characteristics On Employee AC}

Job characteristics refer to a variety of work-related attributes and factors and can draw such attention from management academia mainly due to the following three features:

1. Job characteristics have an effect on employees' job satisfaction and work performance.

2. All studies concerning work have a considerable relation to job characteristics.

3. Job characteristics have a significant effect on the relationship between leadership, job satisfaction, and work performance (Sims, Szilagyi and Keller, 1976).

Therefore, when task uncertainty increases, the amount of information that workers are required to handle will increase accordingly (Griffin, Neal and Parker, 2007). Perrow (1967) also stated that with different job characteristics, employees will encounter different information needs. Therefore, the complexity of job characteristics represents the extent to which employees need to utilize their judgment and interpret diversified information. Perrow (1967) proposed that job characteristics can be described through the two dimensions of analyzability and task variety. As job characteristics can be explored from a variety of perspectives, this study intended to scrutinize them from the perspective of job complexity and discuss the two dimensions of analyzability and task variety. These two dimensions involve investigating what job techniques are required for employees when confronted with different working contexts (Perrow, 1967). Thus, job characteristics are included as an antecedent that may affect employee AC.

Perrow (1967) argued that task variety presents the frequency of exceptions in one's job, with exception of frequency being the uncertainty that the employee encounters in their jobs; namely, the frequency of unexpected and novel events that occur in their work. Job analyzability refers to the possibility of whether the job problems can be solved through standard operating procedure. When the degree of job analyzability is low, it requires individual experience or intuition for judgment. It can be inferred from the definitions of task variety and analyzability that tasks with low level of analyzability and high level of variety are not easy to accomplish; therefore, under the work condition of low level of analyzability and high level of variety, employees can experience quick self-growth and skill accumulation. Additionally, in order to reach the objectives of a low-analyzable and high-variety job, employees will then have stronger motivation for acquiring knowledge. Therefore, this study proposed that low level of analyzability and high level of variety stimulate employees to challenge themselves, constantly promoting their abilities, and being more active at new knowledge absorption, therefore having a positive effect on employee AC in the process of knowledge transfer.

\section{Proposition 5: A low level of task analyzability has a positive effect on employee AC.}

\section{Proposition 6: A high level of task variety has a positive effect on employee AC.}

Based on the two-dimensional measurement criterion of job complexity, including analyzability and task variety, a routine task is one with low level of job complexity (high level of analyzability and low level of task variety). A non-routine task is one with high level of complexity (low level of analyzability and high level of task variety).

A routine task involves the processing of a small amount of simple information, while for a non-routine task with high level of job complexity, it is usually necessary for routine tasks to deal with a large amount of profound information, which will thus require a large number of meetings and instant communication and discussions for problem-solving (Perrow, 1967). Therefore, this study proceeded to propose that, when faced with a highly complex job, employees are inclined to encounter more difficult tasks, consequently, growing more rapidly in 
terms of their competency and becoming more active in the aspect of their knowledge absorption. Therefore, job complexity has a significant effect on employee AC. Propositions are made as follows:

Proposition 7: A high level of job complexity has a positive effect on employee AC.

The Effect Of Organizational Environment On Employee AC

An organization is like a miniature social network where organizational members can, through constant interaction and communication with others, fulfill a variety of different needs at work and obtain a personal sense of belonging. Communication is the process for organizational members to convey messages to each other in order to achieve organizational goals. Therefore, individuals are able to obtain access to necessary information and knowledge for work in the process of formal and informal interpersonal network interaction and communication (Davenport and Prusak, 1998; Minbaeva, 2005). In this study, the design of organizational interaction mechanisms is representative of the organizational environment, or referred to as "whether the organization provides its members with the interaction and communication channels", formal and informal interaction channels included.

As far as formal interpersonal interactions are concerned, most of them are based on the chain of authority and are limited to work-related interactions, such as task groups, job rotations, and company meetings. However, informal interactions are formed based on common interests and goals, such as informal social activities, communities of practice (or knowledge communities) and open space for conversation (Nonaka and Takeuchi, 1995; Stewart, 1997; Wu, Hsu and Yeh, 2007). Stewart (1997) defined a community of practice as "a group of professionals who share a concern or set of problems and get together on an informal basis, and thereby become representative of the expertise in a certain field". In an organizational system with better interaction mechanisms, employees are more likely to have channels and opportunities to exchange their work experience with other members. In addition to the rapid accumulation of knowledge stock, employees will gradually absorb external knowledge and see it as an approach and routine for problem-solving. This study proposed that when the organizational environment has better interaction mechanisms, it will provide employees with the conditions to obtain and share knowledge and thus enhance employees' ability and learning motivation.

\section{Proposition 8: Organizational interaction mechanisms are positively correlated with employee AC.}

Summing up the above literature review, the conceptual framework of this study is shown in Figure 1.

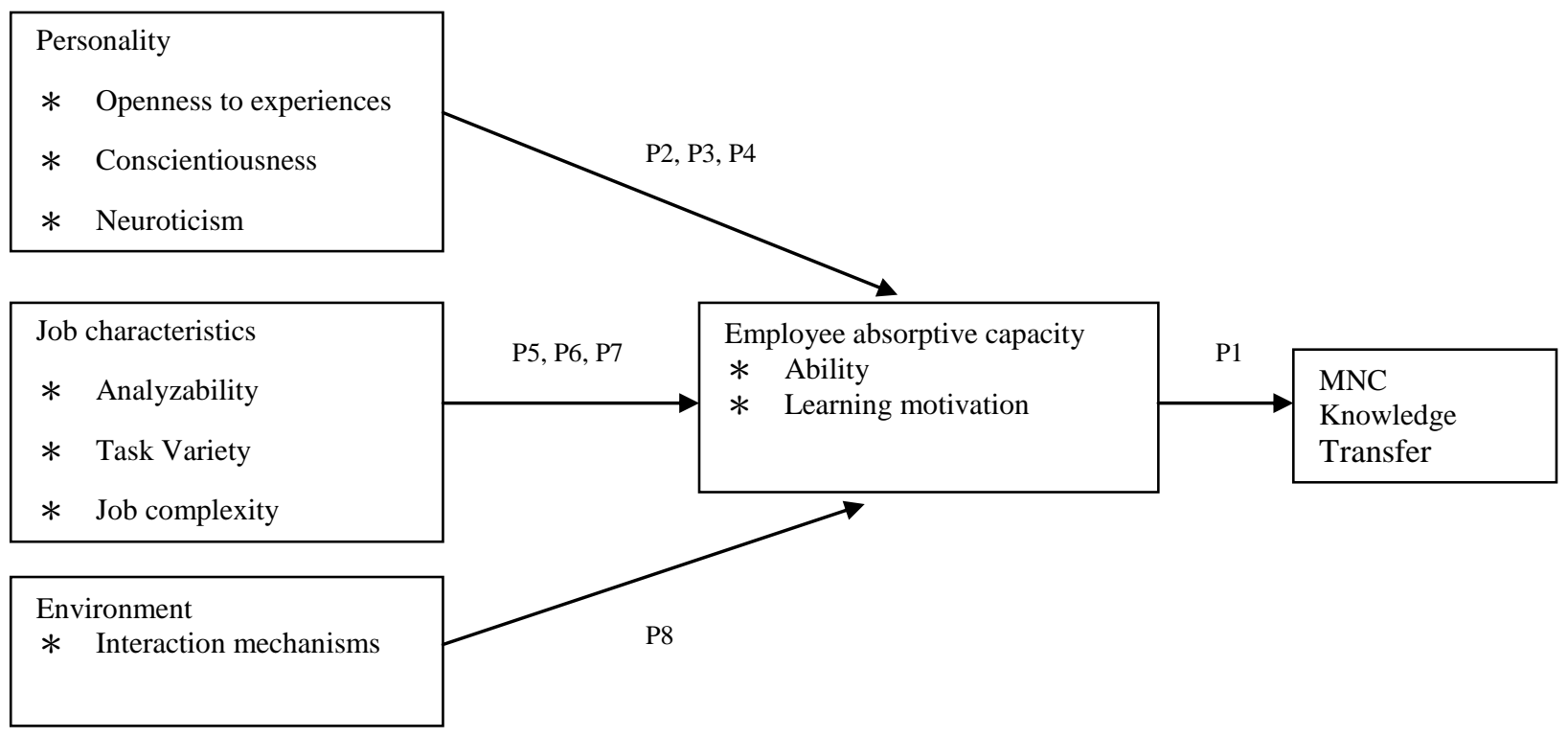

Figure 1: Conceptual Framework 


\section{CONCLUSION AND DISCUSSION}

Since Cohen and Levinthal (1990) proposed the concept of AC for two decades of commitment by many scholars, the $\mathrm{AC}$ research realm has undergone vigorous development. It can be clearly observed that $\mathrm{AC}$ is associated with a number of important management concepts, such as learning, knowledge transfer, dynamic capabilities, etc. (e.g. Lane et al., 2001; Foss and Pedersen, 2004; Lichtenthaler, 2009). Nevertheless, scholars also pointed out that the concept of AC still encounters difficulties behind the development boom (e.g. Lane, Koka and Pathak, 2006; Todorova and Durisin, 2007; Volberda et al., 2010). For example, the concept of AC covers too wide a theoretical scope, resulting in the difficulty of effective measurement. Scholars have mostly measured AC with proxy variables and the research of AC has over focused on the firm level, ignoring individual level AC. Volberda et al. (2010) highlighted that it was necessary to explore an in-depth understanding of the microfoundations of AC. This paper echoed the advocacy of Volberda et al. (2010) and, from an organizational behavior perspective, explored the role of employee AC in MNC knowledge transfer and intraorganizational antecedents at the micro level.

This paper indicated that it is organizational members who conduct the main task of knowledge transfer in MNCs. Thus, it is necessary to further understand employee AC. In the present study, employee AC was classified with the two dimensions of ability and learning motivation, and that employees with high level of AC will be able to be more effective in knowledge transfer. Moreover, from the perspective of organizational behavior, it was proposed that the performance of employee $\mathrm{AC}$ is subject to both the individual and the organizational working environment, respectively shown as individual personality traits, job characteristics and organizational environment. As for personality traits, this study proposed that openness to experience and conscientiousness both have a positive impact on employee AC, while neuroticism has a negative impact on employee AC. With regard to job characteristics, it was proposed that high level of job complexity, low level of analyzability, and high level of task variety may all enhance employee AC. When it comes to organizational environment, it was assumed that if an organization can provide its employees with a good communication system, whether through formal or informal social interaction channels, they can effectively enhance employee AC.

As to managers, the theoretical model developed by this study provides two important views. First, prior research on firm level AC mostly adopted $\mathrm{R} \& \mathrm{D}$ investment as the proxy variable of $\mathrm{AC}$ and then further explored the relationship between AC and MNC knowledge transfer. However, it can be assumed that R\&D investment is not adequate to precisely reflect $\mathrm{AC}$ in an organization, for the practical implementers of knowledge transfer are organization members whose ability and learning motivation can thus better reflect organizational AC. Therefore, it is suggested that management shifts the focus from R\&D investment to knowledge workers in terms of AC. Second, managers can enhance employee AC through management mechanisms. Management may raise the recruitment of employees who incline to have an openness and conscientious personality instead of being neurotic. At the same time, managers can design challenging tasks as a stimulus for employees in order to enhance their AC. Finally, managers can input elements with more personal interaction mechanisms in the organization in order to provide employees with an opportunity to promote AC.

\section{ACKNOWLEDGEMENT}

This research was supported by a grant from the National Science Council of Taiwan under Contract no. NSC 1002410-H-231 -002 -

\section{AUTHOR INFORMATION}

Wei-Li Wu is an Assistant Professor in the Department of International Business at Chien Hsin University of Science and Technology. He received his PhD in International Business from the College of Management at National Chi Nan University in Nantou, Taiwan. His research interests include knowledge management, international business management and organizational behavior. E-mail: wuweili0709@yahoo.com.tw

Yi-Chih Lee is the corresponding author and she received her $\mathrm{PhD}$ in Business Administration from the Fu Jen Catholic University of Taipei, Taiwan. Currently, she is an Assistant Professor in the Department of International 
Business at Chien Hsin University of Science and Technology. Her research interests include health industry management, data mining and customer relationship management. E-mail: lyc6115@ms61.hinet.net. Corresponding author.

\section{REFERENCES}

1. Allport, G. (1961). Pattern and growth in personality. New York: Holt, Rinehart and Winston.

2. Badaracoo, J. (1991). The Knowledge Link: How firms compete through strategic alliances, Boston, Mass: Harvard Business School.

3. Barrick, M.R. \& Mount, M.K. (1991). The Big Five personality dimensions and job performance: a metaanalysis. Personality Psychology, 44(1), 1-26.

4. Björkman, I., Barner-Rasmussen, W. \& Li, L. (2004). Managing knowledge transfer in MNCs: the impact of headquarters control mechanisms. Journal of International Business Studies, 35(5), 443-455.

5. Cohen, W. M. \& Levinthal, D. A. (1990). Absorptive capacity: A new perspective on learning and innovation. Administrative Science Quarterly, 35, 128-152.

6. Costa, P.T., Jr. \& McCrae, R.R. (1992). Revised NEO Personality Inventory (NEO PI-RTM) and NEO

Five-Factor Inventory (NEO-FFI): Professional manual, Odessa, FL: Psychological Assessment Resources.

7. Davenport, T. H. \& Prusak, L. (1998). Working knowledge: How organizations manage what they know. Boston: Harvard Business School Press.

8. Dunning, J. H. (1988). The Eclectic Paradigm of International Production: A Restatement and Some Possible Extensions. Journal of International Business Studies, 19(1),1-31.

9. Edvinsson, L. and Malone, M. 1997. Intellectual capital: realizing your company's true value by finding its hidden brainpower, New York: HarperCollins Publishers Inc.

10. Foss, N. J. \& Pedersen, T. (2004). Organizing knowledge processes in the multinational corporation: an introduction. Journal of International Business Studies, 35(5), 340-349.

11. Griffin, M. A., Neal, A. \& Parker, S. K.(2007). A new model of work role performance: Positive behavior in uncertain and interdependent contexts. Academy of Management Journal, 50, 327-347.

12. Hsu, B.F., Wu, W.L. and Yeh, R.S. (2011). Team personality composition, affective tie and knowledge sharing: a team level analysis, International Journal of Technology Management, 53(2/3/4), 331-351.

13. Lane, P. J. and Lubatkin, M. (1998). Relative absorptive capacity and interorganizational learning. Strategic Management Journal, 19, 461-477.

14. Lane, P.J., Koka, B.R. \& Pathak, S. (2006). The reification of absorptive capacity: a critical review and rejuvenation of the construct. Academy of Management Review, 31(4), 833-863.

15. Lane, P.J., Salk, J.E. and Lyles, M.A. (2001). Absorptive capacity, learning, and performance in international joint ventures. Strategic Management Journal, 22, 1139-1161.

16. Lichtenthaler, U. (2009). Absorptive capacity, environmental turbulence, and the complementarity of organizational learning processes. Academy of Management Journal, 52(4), 822-846.

17. Minbaeva, D., Pedersen, T., Björkman, I., C. F., Fey \& Park H. J. (2003). MNC knowledge transfer, subsidiary absorptive capacity, and HRM. Journal of International Business Studies, 34, 586-599.

18. Minbaeva, D.B. (2005). HRM practices and MNC knowledge transfer. Personnel Review, 34(1), 125-144.

19. Nonaka, I. \& Takeuchi, H. (1995). The knowledge creating company. New York: Oxford University Press.

20. Perrow, C. (1967). A Framework for the Comparative Analysis of Organizations, American Sociological Review, 32(2), 194-208.

21. Robbins, S.P. \& Judge, T.A. (2011). Organizational behavior (fourteenth edition). New Jersey: Pearson Education Inc.

22. Simonin, B. L. (1999). Ambiguity and the process of knowledge transfer in strategic alliances. Strategic Management Journal, 20, 595-623.

23. Sims, H. P., Szilagyi, A. D. \& Keller, R. T. (1976). The measurement of job characteristics," Academy of Management Journal, 19 (2), 195-212.

24. Stewart, T. A. (1997). Intellectual capital: The new wealth of organizations. NY: Doubleday.

25. Szulanski, G. (1996). Exploring internal stickness: Impediments to the transfer of best practice within the firm. Strategic Management Journal, 17(Winter Special Issue), 27-43.

26. Todorova, G. \& Durisin, B. (2007). Absorptive capacity: valuing a reconceptualization. Academy of Management Review, 32(3), 774-786. 
27. Volberda, H.W., Foss, N.J. \& Lyles, M.A. (2010). Absorbing the concept of absorptive capacity: How to realize its potential in the organization field. Organization Science, 21(4), 931-951.

28. Wu, W. L., Hsu, B. F. \& Yeh, R. S. (2007). Fostering the determinants of knowledge transfer. Journal of Information Science, 33, 326-339. 